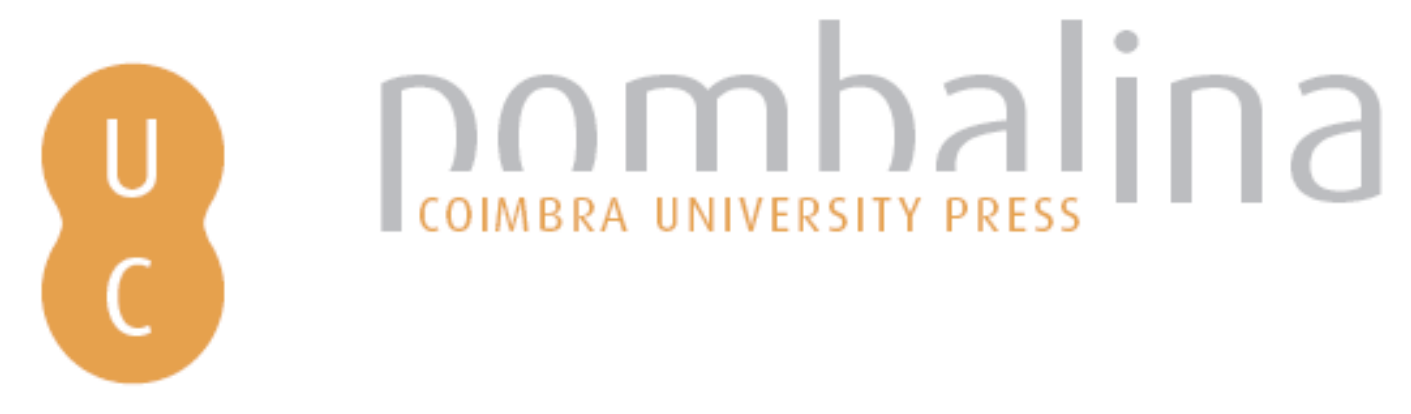

\title{
Monumentalidade e representações do poder tirânico no ocidente grego
}

Autor(es): Hirata, Elaine Farias Veloso

Publicado por: Centro de Estudos Clássicos e Humanísticos; Imprensa da Universidade

URL

persistente: URI:http://hdl.handle.net/10316.2/31504

DOI: $\quad$ DOI:http://dx.doi.org/10.14195/978-989-8281-20-3_2

Accessed : $\quad$ 26-Apr-2023 13:35:44

A navegação consulta e descarregamento dos títulos inseridos nas Bibliotecas Digitais UC Digitalis, UC Pombalina e UC Impactum, pressupõem a aceitação plena e sem reservas dos Termos e Condições de Uso destas Bibliotecas Digitais, disponíveis em https://digitalis.uc.pt/pt-pt/termos.

Conforme exposto nos referidos Termos e Condições de Uso, o descarregamento de títulos de acesso restrito requer uma licença válida de autorização devendo o utilizador aceder ao(s) documento(s) a partir de um endereço de IP da instituição detentora da supramencionada licença.

Ao utilizador é apenas permitido o descarregamento para uso pessoal, pelo que o emprego do(s) título(s) descarregado(s) para outro fim, designadamente comercial, carece de autorização do respetivo autor ou editor da obra.

Na medida em que todas as obras da UC Digitalis se encontram protegidas pelo Código do Direito de Autor e Direitos Conexos e demais legislação aplicável, toda a cópia, parcial ou total, deste documento, nos casos em que é legalmente admitida, deverá conter ou fazer-se acompanhar por este aviso.

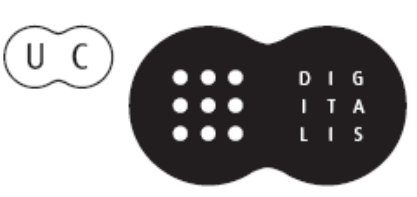




\section{Representações da Cidade Antiga}

categorias históricas e discursos filosóficos

\section{Gabriele Cornelli (Org.)}




\title{
MONUMENTALIDADE E REPRESENTAÇÕES DO PODER TIRÂNICO NO OCIDENTE GREGO
}

Monumentality and Western Greek's Tyrannical Representations

\author{
Elaine Farias Veloso Hirata ${ }^{1}$
}

\begin{abstract}
Resumo: Este texto tem por objetivo apresentar e discutir duas categorias de fontes que documentam as formas de representação do poder tirânico em fundações gregas da Sicília, durante os sécs. VI e V a. C. As evidências materiais testemunham o uso da monumentalidade na construção de templos em épocas de governo tirânico e os epinícios de Píndaro exaltam as vitórias destes governantes nas competições pan-helênicas, constituindo-se, ambos, em instrumentos de propaganda e legitimação de uma forma de poder que já era objeto de crítica por pensadores da época.
\end{abstract}

Palavras-chave: Arquitetura monumental, Sicília, Tirania e Píndaro.

\begin{abstract}
The aim of this text is to present a picture of the two specific documental sources concerning tyrannical representations at the Sicilian Greek foundations during the VI-V centuries B.C. The archaeological evidences witness the use of monumentality in the Sicilian's construction of temples in times of tyrannical government and Pindar's celebratory odes exalts the victories of those governors in Pan-Hellenic competitions, which constituted, in both cases, propaganda instruments of a kind of power already criticized by contemporary thinkers.
\end{abstract}

Keywords: Monumental architecture, Sicily, Tyranny, Pindar's Odes

\section{Espaço, sociedade e arqueologia}

As representações do poder político em sociedades antigas e atuais são veiculadas por meio da palavra, escrita ou oral, da iconografia e também por um grande conjunto de objetos materiais. A arqueologia contemporânea tem no recurso à materialidade como forma de expressão de todo tipo de poder - político, econômico, religioso - uma de suas áreas mais importantes de pesquisa. No caso do mundo antigo, a abordagem tradicional que via na arquitetura principalmente a originalidade e beleza da manifestação artística cede lugar a análises do componente ideológico ${ }^{2}$ (Torelli, 2005: 8-9) que marca essas construções. O dispêndio excepcional de recursos e de energia, transformada em trabalho por grandes contingentes de escravos, bem como a mobilização de artesãos altamente especializados e, por certo bem pagos, implicam uma forma de controle dessas atividades por um poder centralizador forte. É, portanto, necessário analisar as relações entre projetos construtivos, formas de poder e ideologia para que a explanação

\footnotetext{
${ }^{1}$ Professora do Museu de Arqueologia e Etnologia da Universidade de São Paulo (MAE/ USP).E-mail: ehirata@usp.br.

${ }^{2}$ Entendemos ideologia neste texto em uma perspectiva de análise marxista.
} 
arqueológica tenha maior profundidade na análise das formações políticas do mundo antigo.

Dentre os precursores de uma abordagem social do espaço está Gordon Childe, que, já na década de 1950, escreveu: "os homens gradualmente descobrem, por experimentação, como coisas e pessoas podem ser organizadas, definindo então uma idéia de espaço. Então isto deve encontrar um veículo simbólico e ser expresso" (1954: 76). Nessa perspectiva, o ambiente que nos cerca existe em função de nossas ações e dos significados que imprimimos nele; tem, pois, a conotação de um espaço existencial. Já o espaço arquitetônico, o ambiente construído, nada mais é do que a concretização desse espaço existencial.

A relação espaço-sociedade é hoje um tema prioritário na pesquisa arqueológica e vem sendo abordado por estudiosos de várias correntes teóricas. Dentre os de vertentes pós-processualistas, destacaremos aqui aqueles que identificam no chamado espaço construído uma via de comunicação entre grupos sociais hegemônicos ou poderes institucionalizados e os demais grupos de indivíduos integrantes de uma sociedade. Pearson e Richards (1994) observam na forma e disposição das estruturas arquitetônicas na paisagem a manifestação visual da ideologia que dá suporte a relações sociais assimétricas, típicas de sociedades rigidamente hierarquizadas. Para esses autores, portanto, a relação entre ocupação do espaço e expressão de poder é uma via de acesso privilegiada para o estudo da estruturação social e política de uma sociedade.

Assim, na busca do entendimento das interações entre espaço, sociedade, relações de poder, o arqueólogo Bruce Trigger (1990) defende o pressuposto de que, nas construções monumentais, ou seja, naquelas que excedem tanto em escala quanto em qualidade de construção as necessidades funcionais de um edifício, atesta-se o chamado consumo conspicuo, um comportamento que integra as estratégias de afirmação do poder em sociedades estratificadas. Para o autor, nas sociedades humanas, o controle de energia constitui "a mais fundamental e universalmente reconhecida medida de controle de poder", e daí decorre que "o mais básico meio pelo qual o poder pode ser simbolicamente reforçado é através do consumo conspicuo de energia" (1990: 128). ${ }^{3}$ A arquitetura monumental é uma forma de alta visibilidade e durabilidade a comunicar esse consumo extraordinário, associando-o a um governante ou a uma camada hegemônica detentora do poder. Impõe uma mensagem claramente inteligível que sinaliza materialmente para a eternidade e imutabilidade de uma ordem social e, ao negar a possibilidade da mudança, responde ao temor e à ansiedade pela passagem do tempo. As obras monumentais podem efetivamente mascarar o arbítrio com que o poder é exercido clamando por representar a vontade e pensamento coletivos. São edificações que testemunham como esses detentores do poder conseguem

\footnotetext{
${ }^{3}$ Para Trigger, o consumo conspicuo amplia uma perspectiva materialista do comportamento humano ao incorporar "vários aspectos significantes dos componentes ideacionais deste comportamento que aparecem no registro arqueológico” (1990: 132).
} 
dispor de habilidosos artesãos, uma grande monta de recursos materiais e massivas quantidades de trabalho para realizar essas obras. O princípio do consumo conspicuo seria, pois, a contrapartida oposta a outro comportamento muito observado nas sociedades humanas, o princípio do menor esforço, ou seja, o recurso a um gasto maior de energia no tempo curto para reduzir o dispêndio da energia no tempo longo.

\section{Os templos siciliotas e ideologia tirânica}

A seguir, buscaremos analisar a presença de construções monumentais na Sicília grega sob a ótica proposta por Trigger, relacionando esses projetos construtivos aos objetivos propagandístico-ideológicos dos governos tirânicos de duas pólis: Siracusa e Agrigento. Entendemos aqui o conceito ideologia como é definido por Knapp, ou seja, "não só uma reflexão epifenomênica sobre a base político-econômica de uma sociedade, mas como mais um meio pelo qual grupos mantêm, resistem ou mudam ativamente seu poder relativo dentro da sociedade" (1988: 132, grifo nosso). Decorre daí que ideologia e poder estão em contínua e íntima interação e, para que os grupos hegemônicos continuem exercendo seu domínio sobre os demais, a ideologia é reiterada por meio de estratégias e símbolos que usam suportes variados e, dentre eles, os materiais que podem ser acessados pela análise dos arqueólogos. Para Knapp, certos artefatos, como as construções monumentais, como "correlatos materiais" da ideologia, constituem-se em vestígios tangíveis de um "aparato ideológico centralizado" (Knapp, 1996: 16).

Assim, na Sicília (figura 1, a seguir), área onde os gregos fundaram pólis a partir do século VIII a.C., constata-se, entre os séculos VI e V, a introdução de projetos construtivos de escala monumental: os templos. Tais edifícios, muito maiores do que os da Grécia Balcânica, estão localizados em áreas dominadas, ao momento da construção, por governos tirânicos, como é o caso de Siracusa e Agrigento. Desde o final do século XIX, esses sítios foram documentados por trabalhos arqueológicos e, ainda hoje, são estudados tanto com vistas ao conhecimento mais aprofundado da arquitetura antiga, mas, sobretudo, com o intuito de melhor inseri-los no processo histórico que se desenrolou na ilha. Ao lado dos dados oriundos das escavações, temos, dentre as fontes escritas, especialmente Diodoro Sículo (I a.C.) que, ao relatar episódios protagonizados pelos tiranos siciliotas, faz muitas referências a seus projetos construtivos, fornecendo, em certos casos, descrições detalhadas dos trabalhos. ${ }^{4}$

${ }^{4}$ Por ex., Diodoro (XI. 25.2-5), a propósito da construção, pelo tirano Teron de Agrigento, do Olimpiéion e da Kolymbreta nessa pólis. 


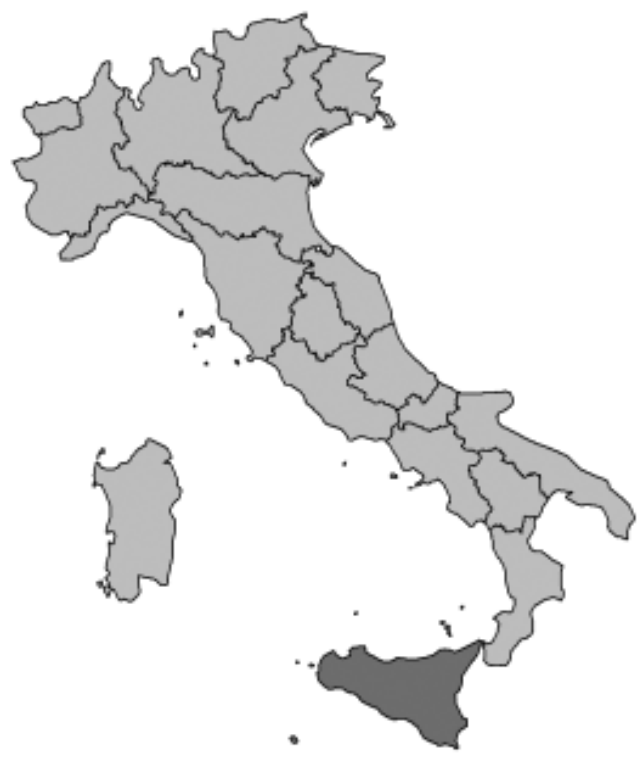

Fig. 1 - Localização da Sicília

\section{A poesia lírica e o poder político}

A poesia lírica, especialmente os epinícios, ${ }^{5}$ que eram as odes cantadas e dançadas por um coro de homens ou meninos em honra de um vitorioso nos Jogos Pan-Helênicos, nos fornecem dados importantes sobre uma das principais formas utilizadas pelos tiranos para divulgar seus projetos políticos e promover sua imagem: a participação nessas competições que eram presenciadas e disputadas por cidadãos de todo o mundo grego (Hirata, 1996-7: 61). Constituem também uma estratégia de auto-representação dos tiranos que envolve a sua aproximação com a figura arquetípica do vencedor-herói, que traz prestígio à pólis de origem. ${ }^{6}$ Sabe-se que os Jogos Pan-Helênicos configuravam-se em espaços de alta visibilidade onde os Estados integrantes da comunidade helênica - representados por seus atletas - competiam vigorosamente em busca da glória e da consagração frente a uma audiência de grande representatividade. Os tiranos da Sicília usaram tais arenas como espaços privilegiados para disputar a admiração, o respeito e conseguir a legitimação de seu poder frente à comunidade grega. A performance do epinício na pólis, no momento do retorno do vitorioso, significa também a incorporação, pela comunidade, da glória do atleta que, ao se estender a todos, reafirmava os laços

5 Segundo Nagy (1990: 142), o termo grego “epiníkion, epinício, significa literalmente alguma coisa como "o que é em compensação pela vitória [nikê]”; o epinício era composto de grupos de três estrofes (tríades) e tinha também três partes: o relato da vitória, desenvolvimento mítico do assunto e por fim o elogio do vencedor e as exortações morais.

${ }^{6} \mathrm{Nagy}$ (1990: 142-3) interpreta as competições pan-helênicas como um programa ritual em honra de um herói que tem na apresentação do epinício o seu estágio final. 
entre ele e a sua pólis (Mc Glew, 1993: 37). Em comemoração às suas vitórias, em geral conseguidas nas modalidades de maior prestígio, como a corrida de carros, os tiranos siciliotas, como Teron de Agrigento e Hieron de Siracusa ${ }^{7}$ comissionavam epinícios a poetas como Píndaro e Baquílides.

A Sicília,vale lembrar, era célebre, já na antiguidade, pela grande quantidade de tiranos que se sucediam praticamente em todas as pólis, e, em certos casos, como Agrigento, tomavam o poder pouco tempo após a fundação. ${ }^{8}$ As pesquisas mais recentes sobre esse fenômeno tentam ultrapassar a tradicional e veemente condenação que os pensadores atenienses do período clássico construíram sobre os tiranos e que permaneceu no pensamento político ocidental. ${ }^{9} \mathrm{Na}$ contramão da maioria dos autores modernos, Sian Lewis (2006) questiona se a permanência de governos tirânicos em várias áreas do Mediterrâneo bem como a sua aprovação por contingentes expressivos da população, como é o caso da aclamação popular de Hieron de Siracusa (Diodoro 11. 26. 5-6; 67. 2. 3), não seriam indicativos relevantes no sentido desse tipo de governo ter vantagens a oferecer, em determinadas circunstâncias. No caso da Sicília, constata-se uma instabilidade político-social endêmica gerada pelos conflitos que os gregos enfrentavam em várias frentes: de um lado a competição entre as próprias pólis pelo domínio territorial e outras tantas rivalidades trazidas das áreas de origem ou iniciadas ali; a disputa com as populações nativas que foram sendo progressivamente deslocadas para o interior diante da expansão das pólis gregas; finalmente a constante ameaça das cidades púnicas que ocupavam a porção ocidental da ilha. Diante desse precário equilíbrio de forças, o poder centralizador de um tirano, aliado a uma capacidade de organizar reações efetivas diante do perigo externo, talvez tivessem sido elementos favoráveis na avaliação dos governados.

\section{Monumentalidade e expressão do poder}

A tirania na Sicília apresenta algumas particularidades que a tornaram uma experiência origina $\mathrm{l}^{10}$ no mundo grego e um dos pontos que merece destaque é a postura imperialista dos seus principais tiranos que, ao assumirem o poder, logo desencadeiam uma política externa agressiva, tentando o domínio das pólis vizinhas utilizando, inclusive, contingentes mercenários. Essa característica é perceptível mais claramente a partir, aproximadamente, dos anos 498 e 491, ${ }^{11}$

${ }^{7}$ Sobre os tiranos siciliotas há várias publicações, mas o estudo mais detalhado e com abordagens inovadoras é de N. Luraghi (1994).

${ }^{8}$ Agrigento teria sido fundada em 580 e já entre os anos 572 e 556 o tirano Fálaris seria documentado na história da pólis (Braccesi, 1998: 5).

${ }_{9}^{9}$ Para N. Bignotto (1998: 13), "A tirania, assim como a democracia é uma invenção grega; invenção cuja radicalidade e originalidade afetaram de maneira significativa a história política do Ocidente".

${ }^{10}$ Luraghi (1994: 377) interpreta a tirania siciliota em analogia com a que se estabeleceu na Ásia Menor: Polícrates de Samos também implementou uma política externa agressiva e usou tropas mercenárias como seus pares da Sicília.

${ }^{11}$ As fontes são controversas quanto à data de início da tirania em Gela. Para esta discussão, ver Luraghi (1994: 119, n. 1). 
com Hipócrates de Gela (Heródoto 7. 154. 1 e 7. 155. 1; Braccesi,1998: 22; Luraghi, 1994: 119 e ss.) que, ao morrer, é sucedido não por um de seus dois filhos, mas por Gelon, eficiente comandante militar que dá início a um longo período de tirania conduzido pela família Deinomênida. ${ }^{12}$ Gelon domina Siracusa e a torna o centro de um império que, no seu ápice, chega a abranger boa parte das fundações gregas.

Gelon torna-se o primeiro tirano siciliota a participar de uma competição pan-helênica: em 488 vence a corrida de quadriga nos Jogos Olímpicos, o que certamente foi capitalizado para legitimar seu acesso ao poder, realizado, na verdade, em prejuízo dos herdeiros naturais de Hipócrates (Luraghi, 1994: 240-1; Van Compernolle, 1959: 316).

Em busca de aprovação ao seu governo, Gelon promoverá uma remodelação urbanística de Siracusa processo que foi qualificado por alguns autores como "a refundação de Siracusa". Para Luraghi (1994: 288), "De fato, a refundação geloniana de Siracusa se apresenta como o único caso em que um tirano, além de impor o seu próprio poder a uma cidade, constrói, ele mesmo, a cidade que dominará".

Heródoto (7. 158) descreve essa ação de Gelon destacando o uso da transferência compulsória ${ }^{13}$ de populações das cidades dominadas (Demand, 1999; Vattuone, 1994) para Siracusa ${ }^{14}$ como estratégia que, de um lado, amplia sobremaneira o número de habitantes, criando uma megalópolis, mas, ao mesmo tempo, suscitando, no futuro, a emergência de focos de tensão social. A magnitude desses deslocamentos compulsórios de população pode ser observada nos dados a seguir: após se instalar em Siracusa, Gelon transfere para lá, a uma distância de $140 \mathrm{~km}$, metade da população de Gela (Heródoto, 7.156) que, naquele momento, podia ser considerada, ao lado de Agrigento, como uma cidade rica da Sicília (Demand, 1999: 47); a seguir arrasa a pólis de Camarina, que se havia rebelado contra o tirano imposto por ele, e também realoca a população sobrevivente em Siracusa (Heródoto, 7. 156), distante $110 \mathrm{~km}$ de Camarina, escravizando-os. Nessa mesma passagem, Heródoto relata que, em Mégara Hibléia, situada a $24 \mathrm{~km}$ de Siracusa, Gelon promoveu também o deslocamento populacional, mas optando por conceder cidadania aos ricos - que haviam liderado uma rebelião - e escravizando os pobres, ou

${ }^{12}$ Gelon assume o poder em Gela por volta de 491-90 e permanece na cidade até c. 485-4, quando instala-se em Siracusa e aí permanece até a morte, em 478-77; Hieron, seu irmão e por ele indicado a sucedê-lo, governa até 467-66.

${ }^{13} \mathrm{O}$ termo grego metoikesis, originalmente usado para mudança individual, aparece em alguns autores antigos referindo-se às cidades: Diodoro Sículo 14.36. 4, a respeito de Magnésia; Diodoro Sículo 15.76. 2; Estrabão 14.2.19, sobre Cós e Diodoro Sículo 13.75. 1, sobre Rodes (apud Demand, 1990: 9).

14 "Senhor de Siracusa, Gelon passou a dar menos importância a Gela, confiando o governo desta a seu irmão Hieron e reservando para si o de Siracusa, que tinha em maior conta. Siracusa desenvolveu-se rapidamente, tornando-se uma das mais florescentes cidades da região. Gelon para ali transferiu todos os habitantes de Camarina, fê-los cidadãos siracusanos e destruiu sua primitiva cidade. Agiu da mesma maneira em relação à maioria dos gelanos. Em seguida, cercou os megarinos da Sicilia, obrigando-os a render-se." 
seja, ampliando seus recursos em força de trabalho e força bélica.

Acreditamos que essas transferências compulsórias de populações possam ser incluídas no fenômeno do “consumo conspícuo", pois, na essência, mobilizam e transferem enormes contingentes de força de trabalho que, eventualmente são utilizados em projetos construtivos na pólis tirânica ou então se transformam no exemplo vivo do poder do governante diante das pólis vizinhas. Em ambos os casos, a figura do tirano aparece, aos seus subordinados, como o poder forte que dá segurança aos seus cidadãos e projeta o nome da cidade.

Tendo sua posição consolidada em Siracusa, Gelon retoma, por volta de 480, com maior empenho, a guerra contra os cartagineses, já em curso desde o início de seu governo. Demand (1999: 45) assim associa dos dois movimentos políticos de Gelon de Siracusa: "os tiranos Deinomênidas da Sicília usaram uma forma de metoikesis - sinecismo físico - para criar instrumentos de poder formidáveis que os capacitaram a enfrentar a ameaça cartaginesa e, ao mesmo tempo, criar uma base de poder para o seu próprio governo."

Neste limiar do VI para o V século, além de Siracusa, outras pólis siciliotas, como Agrigento, encontravam-se em uma fase de crescimento econômico e consolidação do processo de instalação na nova terra. $\mathrm{Na}$ esfera política, Agrigento também convivia com governos tirânicos desde os primeiros tempos de fundação, como vimos anteriormente, e, nesse momento, tinha Teron, da família dos Emênidas no poder. Assim, diante de uma nova investida da armada cartaginesa que, sob o comando de Amilcar, tenta apossar-se de Himera, no momento sob o domínio de Teron de Agrigento, Gelon se alia ao tirano agrigentino ${ }^{15}$ no comando da reação grega ante o perigo púnico.

Heródoto (7. 165-7) relata a célebre batalha de Himera (480 a.C.) vencida pela aliança dos tiranos Teron e Hieron, aproximando-a da vitória grega ante os bárbaros do Oriente: "acrescentam os Sicílianos que, no dia em que os gregos bateram as forças persas em Salamina, Gelon e Teron desafiaram Amílcar na Sicília."

Diodoro Sículo (11. 20-27) apresenta uma descrição mais detalhada do combate, informando-nos que, após o desembarque da frota de Amílcar em Panormo, dirigiram-se os cartagineses e seus aliados para Himera, onde Teron, amedrontado, teria pedido socorro ao tirano siracusano. Gelon, já de sobreaviso, teria, com presteza, vindo em apoio dos agrigentinos e, mais que isso, tornara-se o protagonista da contenda, ao impor aos inimigos a derrota, através de táticas bélicas hábeis e de grande eficácia. Diodoro finaliza sua versão dos acontecimentos relatando o glorioso regresso de Gelon à Siracusa, onde foi aclamado pelo povo com benfeitor e salvador, euerghétes e sóter. $\mathrm{O}$

${ }^{15}$ Uma característica importante nessas alianças entre famílias de tiranos siciliotas é o uso dos casamentos como forma de consolidação do poder: Gelon se casa com uma filha de Teron; depois da morte de Gelon, seu irmão Polizalos casa-se com ela; Hieron, outro irmão de Gelon se casa com a neta de Teron e Teron casa-se com a filha de Polizalos. Assim, no início do séc. $\mathrm{V}$, os principais poderes tirânicos da Sicília se encontram harmonizados por meio de alianças matrimoniais que também estabelecem relações de dependência entre os chefes. A respeito dessa questão e seus desdobramentos na história política da ilha, ver o importante artigo de Louis Gernet (1968: 299-312). 
enaltecimento das figuras dos tiranos e, em especial, dos Deinomênidas é um traço marcante nos textos de Diodoro Sículo, que reafirma o apreço do demos por Gelon relatando que, após a morte do tirano, os siracusanos teriam construído uma tumba monumental para ele e sua esposa Demarete (Diodoro $11.38 ; 14.63)$.

Diodoro (11.26.2), vale lembrar, constitui-se na fonte mais completa sobre esses acontecimentos e é no seu texto que encontramos a menção às condições que os vencedores impuseram aos cartagineses derrotados: o pagamento de uma indenização pequena, dois mil talentos de prata e arcar com os custos da construção de dois templos onde seriam depositadas cópias do tratado de paz. Não há informação no texto sobre os locais onde tais templos deveriam ser erigidos, mas, hoje, acredita-se que seriam Siracusa e Himera. A grande similaridade dos princípios construtivos dos templos dedicados a Atena em Himera, o chamado "Templo da Vitória" (figura 2) e do Athenaion (figura 3) localizado em Ortígia, Siracusa, levou à sua identificação com aqueles mencionados por Diodoro. Os arqueólogos os consideram, do ponto de vista arquitetônico, templos gêmeos, o que indicaria, inclusive, a contemporaneidade da construção, conduzida, talvez, até por um mesmo arquiteto (cf. Mertens, 2006: 256, figs. 464 e 465 ).

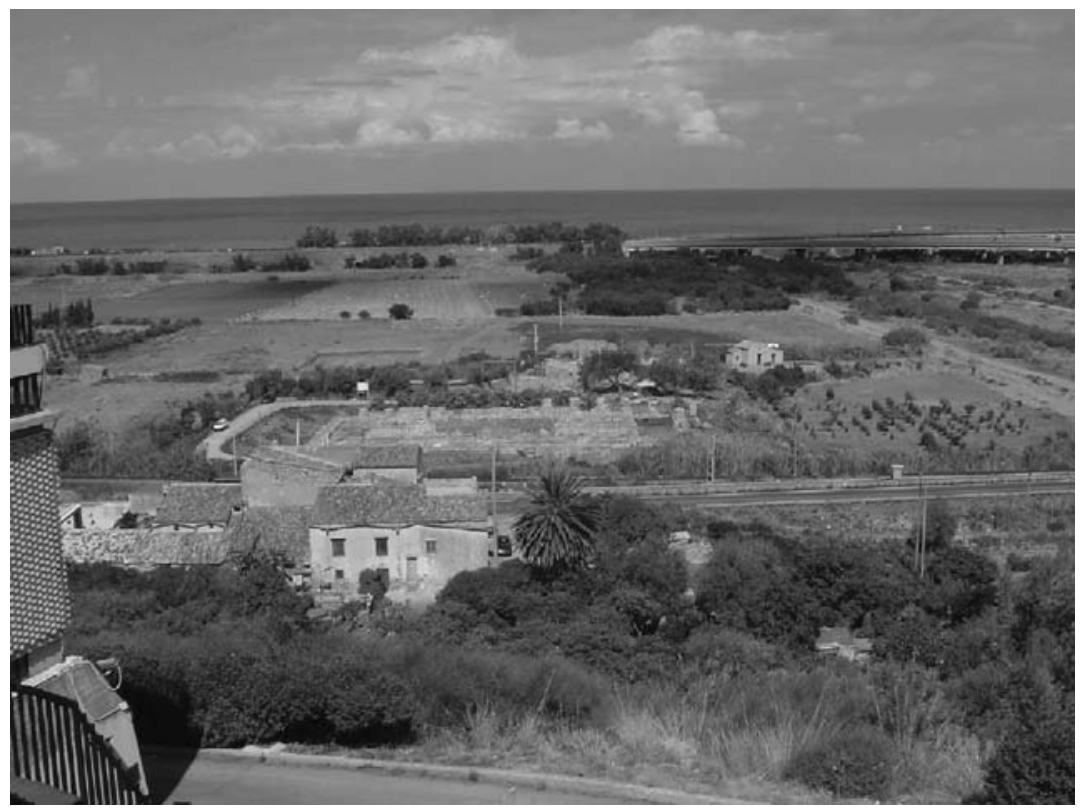

Fig. 2 - Templo da Vitória, em Himera 


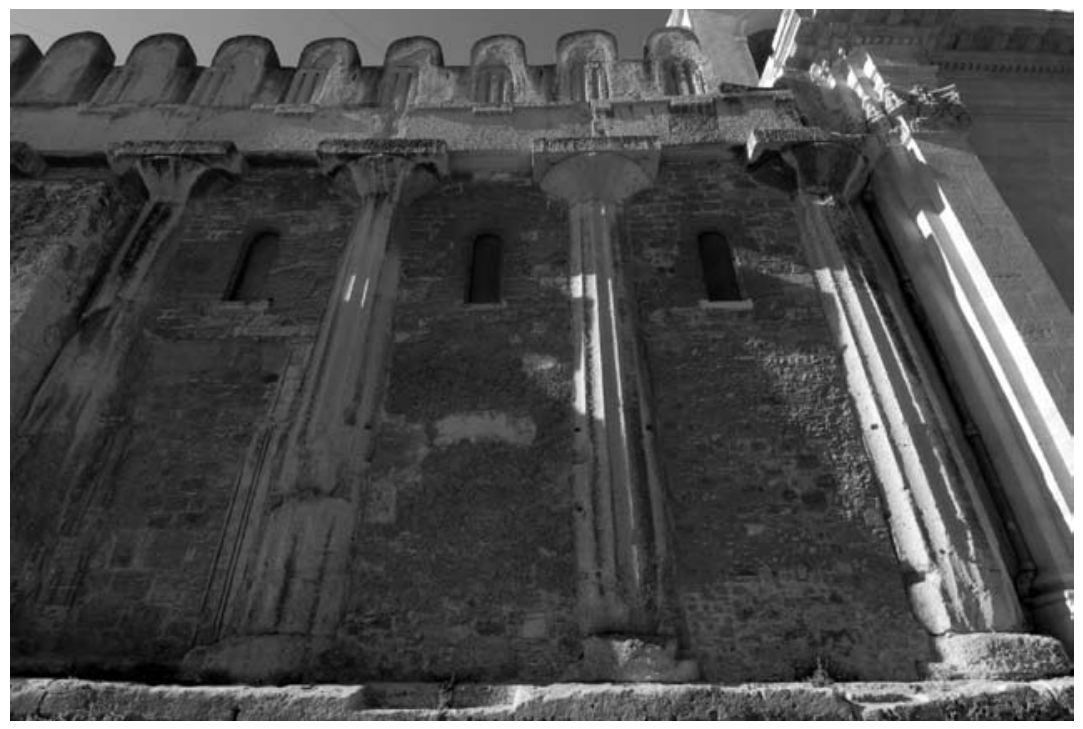

Fig. 3 - Athenaion de Siracusa, atual Duomo da cidade

A localização de cada um é emblemática: o "Templo da Vitória”, de Himera, foi erigido possivelmente nas proximidades ou no próprio campo de batalha, e o Athenaion, na área central de Ortígia, que se constitui na área onde estão os vestígios dos primeiros assentamentos humanos de Siracusa. Nessa área, a chamada Piazza delDuomo, escavada já nos primeiros decênios do século XX, pelo célebre arqueólogo italiano Paolo Orsi, (Voza, 1999: 8-9; figs. 1-4) foram recuperadas, entre 1996 e 1998, pelos novos trabalhos arqueológicos, as fundações do mais antigo edifício de caráter sagrado - o ôkkos - implantado no espaço que " constitui o coração da cidade grega, da medieval e sobretudo, da barroca”(Voza, 1999: 7; fig. 9).

O famoso Athenaion, construído em 480 a.C., ainda hoje é visível, pois sucessivamente foi transformado em igreja cristã e depois na catedral - o Duomo de Siracusa.

Bem, um templo localiza-se perto da cena da batalha, o outro na área sagrada central da cidade governada pelo principal comandante da vitória, mas, e quanto a Agrigento? Diodoro (XI. 25. 1-4) é novamente a fonte que descreve que, aos agrigentinos, coube a maior parte dos prisioneiros de guerra, disponibilizados por Gelon para que Teron pudesse embelezar a sua cidade (Mertens, 2006: 260, fig. 466, 468 e 469). E de fato, os vestígios de um templo excepcionalmente grande são datados de poucos anos após a vitória de Himera. Dedicado a Zeus Olímpico, trata-se de um Olimpiéion ${ }^{16}$ (ver figura 4). A excepcionalidade do Olimpiéion de Agrigento resulta, em primeiro lugar, de suas dimensões: 56,30 x 112,60/70m; perístasis com $7 \times 14$ semicolunas/ pilastras e naos com vigorosas pilastras quadradas; as colunas possivelmente

${ }^{16}$ Diodoro (XIII. 82. 2), em sua posição favorável aos Dinomênidas, descreve em detalhes o edifício. 
teriam medidas entre 19,20 e 21,57m de altura. (ver figuras 5, 6 e 7). Muito significativo também é o tamanho gigantesco do altar, colocado a cerca de $50 \mathrm{~m}$ a leste da entrada do templo e medindo $54 \times 15.70 \mathrm{~m} .{ }^{17}$ Entre o templo e o altar desenhava-se uma área quadrada e ampla que poderia funcionar como uma espécie de esplanada utilizada pelos fiéis quando ocorriam as festividades e sacrifícios em honra de Zeus Olímpio.

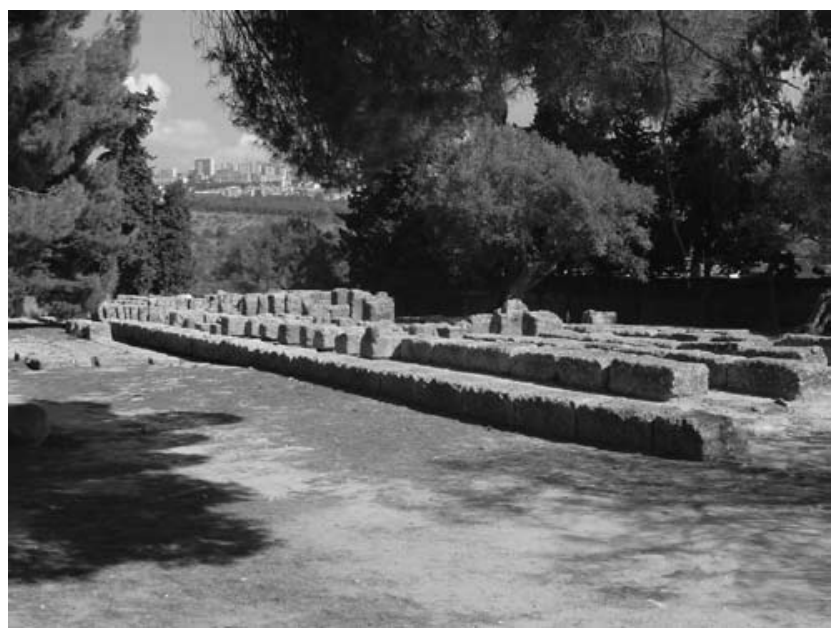

Fig. 4 - Altar do Olimpiéion de Agrigento

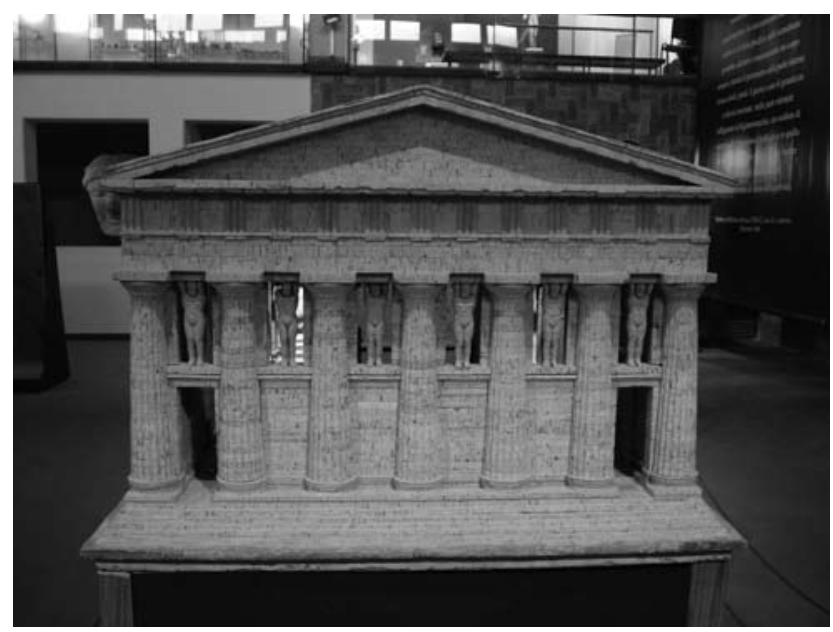

Fig. 5 - Olimpiéion de Agrigento

${ }^{17}$ Mertens (2006: 265) acredita que esse altar tenha sido o mais imponente do Ocidente até a construção do altar de Hieron II em Siracusa. 


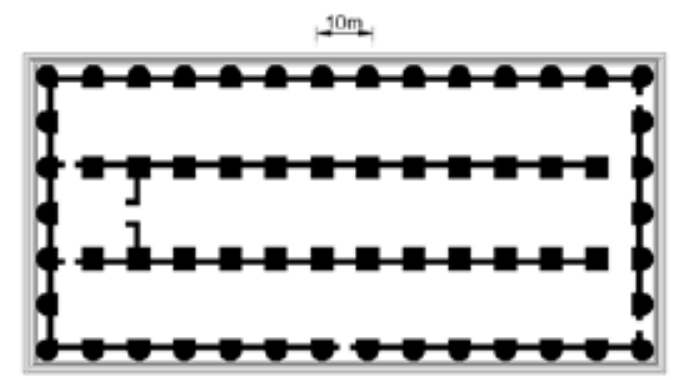

Fig. 6 - Plano de Olimpiéion de Agrigento

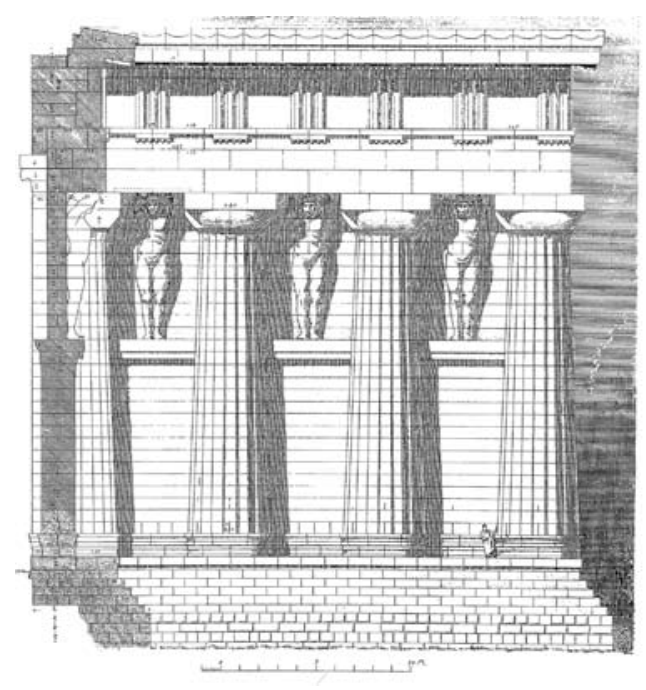

Fig.7 - Olimpiéion de Agrigento

A notícia de Diodoro que dá conta da utilização de grande número de prisioneiros cartagineses para a construção dos templos e principalmente daquele erigido de Agrigento é corroborada por um dos primeiros estudos dessa construção, ainda no século XIX. Trata-se da obra de R. Koldewey e O. Puchstein, Die griechischen Tempel in Unteritalien und Sicilien (1899), da qual Mertens reproduz o seguinte texto:

Pode-se dizer que a sua planta inteira foi calculada de sorte a ser realizada no menor tempo possível por uma imensa quantidade de operários; daí sua monumentalidade e o emprego de muitíssimas pedras e destes dois fatores resultam a implantação pseudo-díptera, a linha de pilastras no interior e, enfim a ornamentação com atlantes (Koldewey; Puchstein, 1899: 165, apud Mertens, 2006: 261). 
Mertens (2006: 265) conclui que, depois de feitas as "observações relativas ao projeto, a cada uma das formas, às suas relações, à técnica construtiva e à organização, o templo poderia ter sido iniciado logo após 480, com a utilização dos meios e dos homens disponibilizados devido a vitória de Himera, para ser construído em brevíssimo tempo."

Novamente aqui, o princípio do consumo conspicuo aparece claramente configurado: o tirano aparece aos seus governados como a figura forte e poderosa que tem sob seu domínio o trabalho de muitos homens e os recursos materiais para construir um edifício de escala monumental que tornar-se-á um emblema da pólis agrigentina frente às demais pólis siciliotas.

A realização sistemática dos rituais de sacrifício no altar monumental que poderia comportar a presença maciça dos agrigentinos com certeza propiciaria a Teron novas oportunidades de reiterar seu poder frente aos cidadãos de sua pólis.

O princípio do consumo conspicuo também poderá ser observado na oferenda de dons valiosos que os tiranos siciliotas faziam aos santuários pan-helênicos - especialmente Delfos e Olímpia. Nesse caso, o objetivo seria a afirmação do poder dos governantes e suas pólis diante da audiência da Grécia balcânica e, ao mesmo tempo, reafirmar o pertencimento ao mundo grego. A vitória de Himera, inclusive, foi aproximada da vitória dos gregos ante os persas em Salamina reiteradas vezes. De um lado, propagandeava-se a coincidência das datas: em um mesmo dia, teria sido rechaçado o perigo bárbaro que ameaçava as fronteiras do mundo grego no Oriente e no Ocidente. Gelon e Teron igualavam-se aos comandantes gregos na vitória que preservava a integridade dos valores gregos nos dois lados do Mediterrâneo.

Além dos templos monumentais erigidos na Sicília para comemorar a derrota dos cartagineses em Himera, Gelon e seu irmão Hieron se fizeram presentes, com grande destaque, no santuário pan-helênico de Delfos, com a oferenda de um monumento valioso, composto de dois grandes trípodes de ouro, assentados em uma base em forma de campânula com uma inscrição epigráfica celebrando a vitória (Mertens, 2006: figura 463). O ex voto foi estrategicamente localizado em frente ao Templo de Apolo, a ser observado por todos que visitavam o famoso santuário. Os Deinomênidas buscam, assim, aproximar sua imagem da de Apolo, o Arquegueta, o Fundador, que foi o grande protetor das fundações gregas no Mediterrâneo e a quem, como indicam as fontes, era obrigatório a consulta antes da partida para as novas terras.

Os siracusanos também buscam registrar sua vitória no santuário pan-helênico de Olímpia. Recolheram e dedicaram os objetos de técnica mais sofisticada, preservados do butim cartaginês e, para armazená-los, fizeram construir um thesauros, que Pausânias descreve, de forma equivocada, como "cartaginês" (figura 8). 


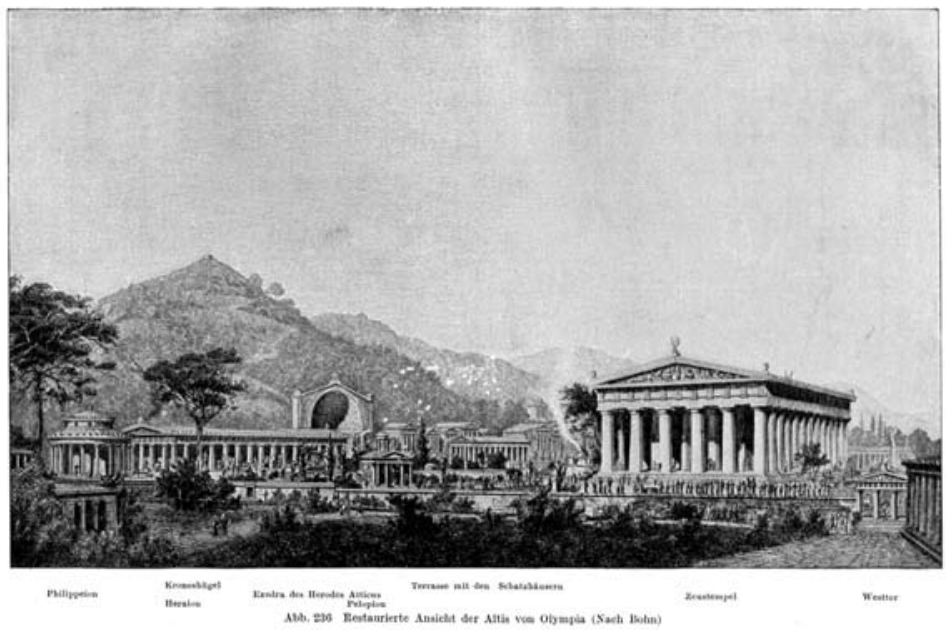

Fig. 8 - Olímpia

O impacto que tais monumentos causavam, ao testemunharem de forma concreta o poderio destes tiranos, deve ser avaliado levando-se em conta que os santuários pan-helênicos eram o cenário mais importante onde as pólis gregas se apresentavam e competiam pelo reconhecimento de suas realizações esportivas, mas, também, e principalmente, de seus êxitos políticos e econômicos.

\section{Discursos do poder: Píndaro}

Ao lado da construção de edifícios sagrados monumentais - os testemunhos diretos do consumo conspicuo como estratégia de representação de poder-os tiranos, como afirmamos inicialmente, se projetavam frente ao mundo grego competindo nos jogos pan-helênicos, e, de preferência, na modalidade mais valorizada: a corrida de carros, que era associada aos valores aristocráticos e heróicos. Veremos agora, como essas vitórias eram amplificadas para a audiência siciliota e da Grécia Balcânica por meio dos epinícios compostos, por encomenda, por poetas líricos como Píndaro $^{18}$ e Baquílides. Gelon não fez uso desse recurso que, por outro lado, foi amplamente instrumentalizado por seu irmão Hieron e Teron de Agrigento.

${ }^{18}$ Sobre Píndaro, ver Ensaios sobre Píndaro, de F. Lourenço (2006), e sua ampla bibliografia. Dentre os escritos de Píndaro, podemos citar: Olimpica 1 - dedicada a Hieron I, celebrando a vitória de seu cavalo - Ferênicos (de Pherênikos, "Portador da Vitória"), em 476; Olimpica 2 dedicada a Teron, por sua vitória também em 476 na corrida de carros; Olímpica 3 - dedicada igualmente a Teron, pela mesma vitória anterior. Na Olimpica 6, dedicada a Agesias de Siracusa, vencedor da corrida de mulas, Píndaro volta a exaltar, nos vs. 93-6, Siracusa e Ortígia como a terra do sábio Hieron. Esses versos foram encontrados inscritos em um antigo tijolo, em Siracusa. Também as Piticas 1, pela vitória em corrida de cavalos, em 470, 2, a Hieron em 477, vencedor da corrida de carros, e 3, também dedicada a Hieron na mesma data. 
Baquílides compôs as odes 3, 4 e 5 para Hieron que também foi homenageado por Píndaro nas Olímpica 1 e Píticas 1, 2 e 3. Para Teron, Píndaro escreveu as Olimpicas 2 e 3 (Mc Glew, 1993: 35 e nota 1).

O epinício era um poema de louvor cujo principal objetivo era situar aquele que o encomendara no centro de uma audiência que seria levada, pelo poeta, a admirá-lo com entusiasmo. A vitória em uma competição olímpica era o mote utilizado pelo autor para associar o vencedor ao universo dos homens excepcionais, capazes de proezas tais que só poderiam vir "dos deuses". $\mathrm{Na}$ Pítica 1 (41- 45), Píndaro afirma que "Todas as formas de virtudes humanas vêm dos deuses" (Mc Glew, 1993: 36, nota 46) e assim a vitória atlética não é concebida como o resultado de uma preparação física rigorosa, pela habilidade do condutor de carros e, sim, como "prêmio" dos deuses a quem o mereça por seu nascimento ilustre, pela sua piedade ou por suas boas realizações. Desta feita, a vitória era uma dádiva divina:

Isto também ajuda a explicar a habilidade do poeta da vitória em louvar os vitoriosos que eram só marginalmente responsáveis por suas vitórias. Entre tais vitoriosos estavam os tiranos que competiam em corridas de carros em Olímpia e Delfos e colecionavam prêmios sem conduzir suas próprias parelhas de cavalos e ainda em alguns casos sem deixar suas casas para testemunhar suas vitórias (Mc Glew, 1993: 36).

O recurso ao epinício se alinha, pois, como estratégia de representação e legitimação do poder tirânico, ao lado do consumo conspicuo. A mesma audiência, a quem o poeta indica a conexão entre a vitória conquistada e o mundo dos deuses e dos heróis, é colocada diante da imagem do templo monumental como a construção magnífica de um homem excepcional - o tirano. Para Leslie Kurke (apud Mc Glew, 1993: 37), o epinício era "um instrumento finamente calibrado para registrar e acomodar o status particular do vitorioso dentro de sua comunidade”, mas Mc Glew amplia essa perspectiva de análise destacando a habilidade do poema em justificar e afirmar as aspirações daquele que o encomendou (Mc Glew, 1993: nota 48). Trata-se, enfim, de estreitar os laços entre o poder político e a comunidade por meio de instrumentos de comunicação que se valem de variados suportes.

Em síntese, podemos concluir que os tiranos nas áreas ditas "coloniais" instituíram sistemas de representação e legitimação de seu poder político usando, de um lado, o cenário de suas pólis. Inscreveram, no espaço público, edificações sagradas - os templos monumentais - que funcionaram como claros e duradouros marcos ideológicos, vetores da imbricação entre a religião e a política tão característica do mundo helênico. Nessa perspectiva objetivaram a comunicação com o público local, mais próximo, os seus governados e as pólis siciliotas vizinhas com que viviam em clara competição desde as primeiras fases de implantação dos assentamentos. Esse contingente mais próximo incluía também as populações nativas que, em muitos casos, haviam sido afastadas de seus espaços originais. 
A busca de legitimação voltou-se concomitantemente para o mundo grego, com os tiranos participando das competições atléticas pan-helênicas e comissionando epinícios, cuja audiência incluía os cidadãos das pólis por eles governadas e as demais pólis do mundo grego.

Voltando à questão da monumentalidade, podemos concluir com o que talvez seja o exemplo maior na manifestação do consumo conspicuo entre os tiranos siciliotas. O irmão de Gelon de Siracusa, Hieron, não satisfeito em criar monumentos, fundou uma "nova' cidade - Etna, onde anteriormente estava implantada Catânia (Diodoro Sículo, 11.49.1-3). Tornou-se, então, um verdadeiro oikista e aí atingiu o objetivo que provavelmente todos os demais perseguiram: foi sepultado na ágora da nova pólis e, de acordo com Diodoro (XI, 66, 1-67) recebeu as honras devidas a um herói.

\section{Bibliografia}

Bignotto, N. (1998). O Tirano e a cidade. São Paulo, Discurso Editorial.

Braccesi, L. (1998). I tiranni di Sicília. Roma: Editori Laterza.

Bruno, G. (2005). Aristocracia, tirania e democracia, em Minà. in Urbanistica e Architettura nella Sicília Greca. Palermo: Assessorato dei Beni Culturali ambientali e della pubblica istruzione /Dipartimento dei Beni Culturali, Ambientali e della Pubblica Istruzione, 15-22.

Childe, V. G. (1954). Society and Knowledge. Westport: Conn. Greenwood.

Demand, N. H. (1999). Urban relocation in Arcaic and classical Greece. Flight end Consolidation. Londres: Routledge.

Diodorus Siculus. (1993). Library of History (9 vols). Oldfather, C. H. (ed. e trad.). Cambridge: Harvard University Press (Loeb Classical Lybrary).

Gernet, L. (1968). Marriage de tyrans. in Gernet, L. Antropologie de la Grèce antiqúe. (1954) Paris: Maspero, 299-312.

Heródoto. (2001). História: O relato clássico da Guerra entre Gregos e Persas. 2. ed. Tradução de J. Brito Broca. São Paulo: Ediouro.

Hirata, E. F. V.(1996-1997). As odes de Píndaro e as tiranias siciliotas. Classica, Belo Horizonte, v. 9/10, 61-72.

Knapp, A. B. (1988). Ideology, Archaeology and Polity. Man, New Series, v. 23, n. 1, London, Royal Anthropological Institute of Great Britain and Ireland, 133-163.

Knapp, A. B. (1996). Power and Ideology in Prehistoric Cyprus. in Hellström, P.; Alroth, B. (eds.). Religion and Power in the Ancient Greek World. Boreas, n. 24, Uppsala, 9-25. 
Kurke, L. (1991). The Traffic in Praise. Pindar and the Poetics of Social Economy. Ithaca: Cornell University Press.

Lewis, S. (2006). Ancient tyranny. Edinburgh : Edinburgh University Press.

Lourenço, F. (Ed.). (2006). Ensaios sobre Pindaro. Lisboa: Cotovia.

Luraghi, N. (1994). Tirannidi arcaiche in Sicilia e Magna Grécia. Firenze: L.S. Olschki.

McGlew, J. F. (1993). Tyranny and Political Culture in Ancient Greece. Ithaca: Cornell University Press.

Mertens,D.(2006). Città e monumenti dei Grecid' Occidente.Dalla colonizzazione Allá crisi di fine $V$ secolo a. C.. Roma: L'Erma di Bretschneider.

Miná, R. M. P. (2005). Urbanistica e Architettura nella Sicília Greca. Palermo: Regione Siciliana. Dipartimento dei Beni Culturali, Ambientali e della Pubblica Istruzione

Nagy, G. (1990). Pindar's Homer. The Lyric Possession of an Epic Past. Baltimore: The Johns Hopkins University Press, 1990.

Pearson, M. P.; Richards, C. (eds.) (1994). Architecture and Order Approaches to Social Space. Londres: Routledge.

Torelli, M. (2005). Archeologia greca di Sicilia: il ruolo dell'ideologia.in: Minà, P. Urbanistica e Architettura nella Sicília Greca, 8-9.

Trigger, B. (1990). Monumental Architecture: A Thermodynamic Explanation of Symbolic Behavior. World Archaeology, 22, 2, 119-132.

Van Compernolle, R. (1959). Étude de chronologie et d'bistoriographie siciliotes. Bruxelas-Roma: Institut Historique Belge de Rome.

Vattuone, R. (1994). 'Metoikesis' Trapianti di popolazioni nella Sicilia greca fra VI e IV sec. a. C. Vita e Pensiero, n. 57, 81-113.

Voza, C. (1999). A Guide to Syracuse. Syracuse: Ediprint. 